\title{
Evaluation of a 35 GHz Radar for Cloud Physics Research*
}

\author{
Peter V. Hobis, Nathan T. Funk, ${ }^{1}$ Richard R. Weiss, SR., ${ }^{2}$ John D. LOCATElli \\ AND KUMUD R. BISWAS \\ Department of Atmospheric Sciences, University of Washington, Seattle, WA 98195
}

(Manuscript received 9 January 1984, in final form 28 September 1984)

\section{ABSTRACT}

\begin{abstract}
A $196035 \mathrm{GHz}$ radar has been modernized through the use of solid state electronics, Dopplerization and improved data-display capabilities. Radars of this frequency are particularly useful for observing the internal structures of clouds and for detecting low concentrations of ice particles in the atmosphere.

The minimum effective radar reflectivity factor of a cloud of water drops that is measurable by this radar at a range of $1 \mathrm{~km}$ was estimated to be $-36 \pm 4 \mathrm{dBZ}$. Simultaneous airborne and radar measurements showed that the radar reflectivity factors for various water clouds determined from radar measurements were generally in good agreement with those derived from in situ measurements of the drop size spectra. These measurements also showed that the radar can detect clouds in which the diameters of the droplets do not exceed $\sim 27 \mu \mathrm{m}$ provided there are sufficient concentrations of $10-15 \mu \mathrm{m}$ diameter droplets. Clouds containing only $1 \mathrm{~L}^{-1}$ of $100 \mu \mathrm{m}$ diameter ice crystals (corresponding to a mass concentration of $\sim 10^{-3} \mathrm{~g}$ $\mathrm{m}^{-3}$ ) are detectable by the radar.

Due to its narrow beamwidth $\left(0.26^{\circ}\right)$, reflectivity measurements with the $35 \mathrm{GHz}$ radar can reveal more detailed structural information on clouds and precipitation than more powerful $5.5 \mathrm{GHz}$ radars.

The $35 \mathrm{GHz}$ radar has been Dopplerized using a new magnetron phase correlation technique that allows detailed measurements to be obtained of the velocities of particles down to $\sim 25 \mathrm{~cm} \mathrm{~s}^{-1}$. Some examples are presented of measurements of the spectra of the vertical velocities of cloud particles using this technique.
\end{abstract}

\section{Introduction}

Radar studies of clouds and precipitation have been confined, for the most part, to radars with wavelengths $\lambda$ greater than $1.25 \mathrm{~cm}$. Such radars can detect particles with sizes down to $\sim 100 \mu \mathrm{m}$ with reasonable sensitivity. However, smaller cloud particles are more readily detected by shorter wavelength radars (i.e., "millimeter-wave" radars). At these wavelengths, radars are limited by atmospheric absorption to two "windows," one at $\sim 35 \mathrm{GHz}(\lambda \approx 8.6 \mathrm{~mm})$ and the other at $90 \mathrm{GHz}(\lambda \approx 3.3 \mathrm{~mm})$.

Recent advances in electronics have made $90 \mathrm{GHz}$ radars possible and their use for atmospheric studies is a topic of current research (Lhermitte, 1981). Powerful millimeter-wave radars, on the other hand, have been available for over 30 years, and they were used quite widely for cloud and precipitation studies in the 1950s (e.g., Plank et al., 1955; Boucher, 1959; Wexler and Atlas, 1959). They then suffered a period of decline, as attention centered on the use of longer wavelength radars. However, recent technological developments in low-noise receiver components, techniques for Dopplerization and improved data display

\footnotetext{
' Present affiliation: Aromet Inc., Tulsa, OK 74157.

${ }^{2}$ Present affiliation: Seattle University, Seattle, WA 98122.

* Contribution No. 711 of the Department of Atmospheric Sciences, University of Washington.
}

capabilities have resulted in a resurgence of interest in $35 \mathrm{GHz}$ radars for meteorological research (Sauvageot, 1982; Pasqualucci et al., 1983.)

In this paper we describe the modernization, evaluation and preliminary use of a $196035 \mathrm{GHz}$ radar. The ability to detect thin, nonprecipitating clouds with this radar has been explored by comparing radar reflectivities with simultaneous, in situ airborne measurements of cloud particles. The radar has also been compared with $5.5 \mathrm{GHz}(\lambda=5.5 \mathrm{~cm})$ radar. Finally, the radar has been Dopplerized using a new magnetron phase correlation (MPC) technique. This provides measurements of the velocities of cloud particles down to $\sim 25 \mathrm{~cm} \mathrm{~s}^{-1}$, even in very low reflectivity clouds. Comparisons of velocities measured with the MPC technique and a conventional $(5.5 \mathrm{GHz})$ Doppler radar show good overall agreement, but with greater detail provided by the $35 \mathrm{GHz}$ radar.

\section{The University of Washington $35 \mathrm{GHz}$ radar \\ a. General description}

The University of Washington (UW) $35 \mathrm{GHz}$ radar was derived from a U.S. Air Force AN/TPQ-11 reflectivity radar (Petrocchi and Paulsen, 1966; Paulsen et al., 1970).

The radar is vertically pointing and bistatic. It has separate transmitting and receiving antennas, each 
TABLE 1. Characteristics of the University of Washington's 35 $\mathrm{GHz}$ radar and NCAR's $5.5 \mathrm{GHz}(\mathrm{CP}-4)$ radar.

\begin{tabular}{lll}
\hline \multicolumn{1}{c}{ Parameter } & \multicolumn{1}{c}{$\begin{array}{c}35 \mathrm{GHz} \\
\text { radar }\end{array}$} & $\begin{array}{c}5.5 \mathrm{GHz} \\
(\mathrm{CP}-4) \text { radar }\end{array}$ \\
\hline Wavelength (cm) & 0.86 & 5.5 \\
Peak power* (kW) & 140 & 316 \\
Pulse repetition frequency & 1000 or 4000 & 769.2 or 1000 \\
Pulse length ( $\mu$ s) & 0.5 & 1.0 \\
Receiver bandwidth (MHz) & 5 & 10 \\
Minimum measurable signal, & & \\
$\quad \bar{P}_{\min }(\mathrm{dBm})$ & -85 & -105 \\
Antenna diameter (m) & 2.13 & 3.7 \\
Beamwidth (deg) & 0.26 & 1.05 \\
\hline
\end{tabular}

* At a pulse repetition frequency of $1000 \mathrm{~Hz}$.

† Logarithmic channels.

$2.13 \mathrm{~m}$ in diameter, resulting in an extremely narrow beamwidth $\left(0.26^{\circ}\right)$ and fine spatial resolution in the measurements. The transmitter employs a magnetron oscillator with a peak power of $\sim 140 \mathrm{~kW}$ at a pulse repetition frequency (prf) of $1000 \mathrm{~Hz}$. However, to extend the life of the magnetron, we generally do not exceed a power output of $80 \mathrm{~kW}$. Other characteristics of the radar are listed in Table 1.
Initially, we used the radar essentially in its original Air Force configuration for measuring cloud top heights and found it to be superior, for this purpose, to a $9.4 \mathrm{GHz}(\lambda=3.2 \mathrm{~cm}$ ) radar (Weiss et al., 1979). Subsequently, the electronics, data processing and data display capabilities of the radar were upgraded. The receiver electronics were improved by replacing the klystron local oscillator with a solid-state, phaselock Gunn diode, stable local oscillator (STALO). Also, an ultra low-noise, intermediate frequency (IF), preamplifier mixer was used in place of the original mixer.

\section{b. Dopplerization}

We have used a unique implementation of the MPC technique, first described by Nutten et al., (1979), for Dopplerizing the $35 \mathrm{GHz}$ radar. In this technique sufficient information is stored on the phase of the transmitted pulse to allow the random phase of the magnetron to be eliminated mathematically. This technique is implemented on our $35 \mathrm{GHz}$ radar through the use of analog, sample-and-hold, multiplier and adder circuitry (Fig. 1) with 8-bit digitization occurring at the prf.



FIG. 1. Block diagram of the magnetron phase correlation technique used for Dopplerizing the $35 \mathrm{GHz}$ radar. 
The transmitted signal is translated down in frequency by mixing it with the microwave signal from the STALO. The resulting IF signal goes through the reference isolation switch, controlled by the timer/ clock. The phase of the transmitted pulse is compared with that of a coherent oscillator (COHO) and stored by a sample-and-hold circuit. The received pulse is translated in frequency with a low-noise mixer and the resulting IF signal passed through the reference isolation switch and also compared with the COHO. The phase of the received pulse is then stored by the range gate, sample-and-hold circuit for mathematical processing. When digitized at the prf of the radar, this produces a complex time series from which the Doppler spectrum can be derived.

\section{c. Data processing}

The signal received by the radar is split into two parts, one going to the Doppler processing circuits and the other to a logarithmic receiver via a manual attenuator for processing of the reflectivity data (Fig. 2 ). One reflectivity value is digitized for each transmitted pulse. Although the pulse width $(0.5 \mu \mathrm{s})$ represents a distance of $75 \mathrm{~m}$, range gates are set at $37.5 \mathrm{~m}(0.25 \mu \mathrm{s})$ intervals. The received signal is sampled every 1 prf $^{-1}+0.25 \mu \mathrm{s}$ by a sample-and-

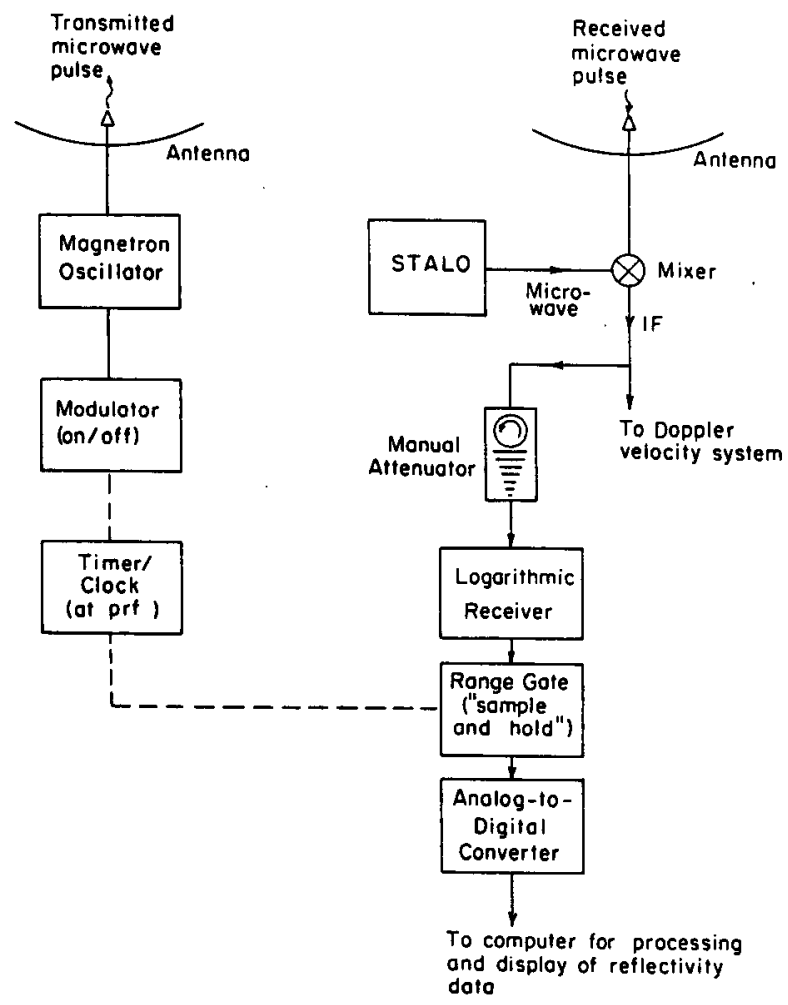

FiG. 2. Block diagram of the $35 \mathrm{GHz}$ radar depicting the reflectivity components of the total system. hold circuit and then digitized by an 8-bit converter. A minicomputer is used to format the data so that it can be recorded on 9-track magnetic tape.

A complete reflectivity ray, consisting of 512 values (corresponding to a maximum vertical range of 19.2 $\mathrm{km}$ ), requires $512 \mathrm{~ms}$ to process at a prf of $1000 \mathrm{~Hz}$. This time period is sufficiently short for each ray to be considered instantaneous, and they are treated as such in processing and displaying the data. Because the minicomputer is also used to process the Doppler velocity data, it can record only one reflectivity ray every $3 \mathrm{~s}$. The combined sets of reflectivity and velocity data are recorded on magnetic tape for subsequent analyses.

The minicomputer also controls a color graphics system. This is used for the real time display of both reflectivity and mean Doppler velocity data. Computer software allows the user to select from many types of displays. The reader is referred to Hobbs and Funk (1984) for illustrations of the types of color reflectivity displays obtainable from this system.

In deriving velocity data, a time series of 128 digital, complex values (each value corresponding to the return signal from a transmitted pulse) is processed by the computer. At each range gate this time series is converted (by a fast Fourier transform) into a frequency spectrum, with 128 data points, and then recorded on magnetic tape.

The computer can process seven range gates in 3 s. The spacing and positioning of the range gates, and the upper and lower limits of the vertical heights of the radar scans, are specified by the operator. The positions of the range gates can be overlaid (in colored-coded dots) on the simultaneously measured radar reflectivity pattern displayed in grey shades; the color coding of the dots provides a measure of the mean Doppler velocity at each height.

\section{Radar reflectivity calibrations and sensitivities}

Radars with steerable antennas can be calibrated by measuring the fraction of the transmitted power that is scattered back to the radar from a target of known back-scattering cross section (e.g., a metal sphere). Alternately, measurements may be made of the power received by the radar from a source of known electromagnetic output (e.g., the sun). Since our $35 \mathrm{GHz}$ radar has two fixed, vertically-pointing antennas, neither of these methods of calibration is practical. In Section 4, we will present the results of comparisons of the reflectivities of clouds measured with the UW radar and a steerable radar. In the present section we will describe attempts to calibrate the $35 \mathrm{GHz}$ radar and to determine its sensitivity.

\section{a. Water clouds}

The effective radar reflectivity factor $Z_{e}$ was determined using the relation (Battan, 1973): 


$$
\mathrm{Z}_{e}=\frac{1}{C} \frac{r^{2} \bar{P}}{|K|^{2}}
$$

where $C$ is a constant that depends on the characteristics of the radar, $\bar{P}$ the average returned power, $r$ the range of the scatterers, and $|K|^{2}$ the dielectric factor for the scatterers. For our $35 \mathrm{GHz}$ radar, $C$ $\approx 1.6 \times 10^{14} \mathrm{~W} \mathrm{~cm}^{-1}$, and, for water drops at 35 $\mathrm{GHz}$ and $0^{\circ} \mathrm{C},|K|^{2}=0.87$ (Battan, 1973). The minimum measurable averaged return power for the radar is about $-85 \pm 4 \mathrm{dBm}$. Hence, for a water cloud at a range of $1 \mathrm{~km}$ from the radar, the minimum value of $Z_{e}$ that can be measured is -36 $\pm 4 \mathrm{dBZ}$.

Additional information on the calibration of the radar, as well as its sensitivity in detecting cloud droplets, was obtained from airborne measurements of droplet size spectra in clouds that were either just detectable or just not detectable by the radar. The instrumentation aboard the aircraft (the UW B-23) that provided the required measurements were the particle measuring systems (PMS) axially-scattering spectrometer probe, and the one- and two-dimensional cloud probes (Knollenberg, 1981). Clouds were chosen that were sufficiently thin that aircraft penetrations of the clouds were visible from the radar. Only data frorn clouds that were directly over the radar during aircraft penetrations were used. Even so, it should be noted that the volume of the cloud sensed by the radar was $\sim 1000 \mathrm{~m}^{3}$, while that sampled by the aircraft probes was only $\sim 100 \mathrm{~cm}^{3}$. This large difference can result in considerable uncertainties in the comparison between the radar and airborne measurements.

The results of measurements obtained in thin, nonprecipitating cumulus humilis clouds on two days (26 March and 3 April 1981) are summarized in Table 2. Liquid water contents (derived from the PMS probes) ranged from $<0.004$ to $0.12 \mathrm{~g} \mathrm{~m}^{-3}$. The mean diameters of the droplets varied from $\sim 5-8$ $\mu \mathrm{m}$. No droplets with diameters $>27 \mu \mathrm{m}$ and no ice particles were detected in any of the clouds.

The sixth column in Table 2 indicates whether the cloud was detected visually on the A-scope connected directly to the receiver output of the radar. The data recording system was set to record any reflectivity that exceeded the noise level of the receiver. However, it was possible to visually detect signals just at the noise level of the receiver, even though these were not recorded. If a cloud was recorded by the data system it is referred to as "measurable," as shown in the third-to-last column in Table 2.

Since the wavelength of the $35 \mathrm{GHz}$ radar is 1075 tirnes greater than the maximum mean diameter of the cloud particles listed in Table 2, scattering was well within the Rayleigh region. Therefore, the radar reflectivity factor $Z$ of the cloud is given by (Battan, 1973):

TABLE 2. Simultaneous measurements with the $35 \mathrm{GHz}$ radar and B-23 aircraft of thin, nonprecipitating cumulus humilis clouds.

\begin{tabular}{|c|c|c|c|c|c|c|c|c|}
\hline $\begin{array}{c}\text { Date } \\
(1981)\end{array}$ & $\begin{array}{c}\text { Time } \\
\text { (h:min:s) }\end{array}$ & $\begin{array}{l}\text { Flight } \\
\text { level } \\
(\mathrm{km})\end{array}$ & $\begin{array}{l}\text { Liquid } \\
\text { water } \\
\text { content } \\
\left(\mathrm{g} \mathrm{m}^{-3}\right)\end{array}$ & $\begin{array}{l}\text { Mean } \\
\text { droplet } \\
\text { diameter } \\
(\mu \mathrm{m})\end{array}$ & $\begin{array}{l}\text { Cloud } \\
\text { detected } \\
\text { by A-scope } \\
\text { on radar? }\end{array}$ & $\begin{array}{l}\text { Cloud } \\
\text { measurable } \\
\text { by radar? }\end{array}$ & $\begin{array}{l}\text { Radar reflectivity factor } \\
\text { (Z) calculated from } \\
\text { aircraft measurements } \\
\text { [dBZ] }\end{array}$ & $\begin{array}{l}\text { Radar reflectivity factor } \\
\left(\mathrm{Z}_{e}\right) \text { derived from radar } \\
\text { measurements [dBZ] }\end{array}$ \\
\hline 26 March & $09: 45: 26$ & 0.88 & 0.04 & 5.7 & Yes & No & -44 & - \\
\hline 26 March & $09: 48: 26$ & 0.94 & 0.02 & 6.3 & Yes & No & -44 & - \\
\hline 26 March & $09: 51: 42$ & 1.16 & 0.05 & 8.0 & Yes & Yes & -38 & $-36 \pm 4$ \\
\hline 26 March & 09:55:36 & 1.16 & 0.12 & 7.9 . & Yes & Yes & -35 & $-36 \pm 4$ \\
\hline 26 March & $10: 02: 42$ & 0.91 & 0.02 & 5.8 & Yes & No & -46 & - \\
\hline 26 March & 10:08:54 & 0.94 & 0.05 & 6.0 & No & No & -43 & - \\
\hline 26 March & $10: 18: 18$ & 0.94 & 0.02 & 5.6 & Yes & No & -47 & - \\
\hline 26 March & $10: 20: 51$ & 0.91 & 0.02 & 6.0 & Yes & No & -46 & - \\
\hline $26 \mathrm{March}$ & $10: 29: 18$ & 0.88 & 0.02 & 5.5 & Yes & No & -46 & - \\
\hline 26 March & $10: 37: 42$ & 0.94 & 0.004 & 5.4 & No & No & -57 & - \\
\hline 26 March & $10: 47: 54$ & 1.01 & 0.05 & 6.0 & Yes & Yes & -44 & $-37 \pm 4$ \\
\hline 26 March & 10:51:06 & 1.40 & 0.04 & 5.8 & Yes & No & -44 & - \\
\hline 26 March & $10: 57: 06$ & 1.16 & 0.03 & 5.7 & Yes & No & -45 & - \\
\hline 26 March & 11:00:42 & 1.07 & 0.10 & 6.3 & Yes & No & -39 & - \\
\hline $26 \mathrm{March}$ & $11: 03: 30$ & 1.04 & 0.12 & 6.2 & Yes & No & -38 & - \\
\hline 26 March & $11: 06: 30$ & 1.04 & 0.04 & 5.8 & Yes & No & -44 & - \\
\hline 3 April & $09: 41: 46$ & 0.67 & 0.07 & 7.0 & Yes & Yes & -40 & $-40 \pm 4$ \\
\hline 3 April & $09: 44: 40$ & 0.70 & 0.07 & 7.3 & Yes & Yes & -40 & $-40 \pm 4$ \\
\hline 3 April & 09:54:20 & 0.76 & 0.07 & 5.9 & Yes & Yes & -41 & $-37 \pm 4$ \\
\hline 3 April & $09: 57: 35$ & 0.70 & 0.07 & 6.0 & Yes & Yes & -40 & $-40 \pm 4$ \\
\hline 3 April & $10: 03: 35$ & 0.79 & .0 .03 & 6.0 & No & No & -40 & - \\
\hline 3 April & $10: 06: 55$ & 0.88 & $<0.004$ & 6.3 & No & No & -55 & - \\
\hline 3 April & $10: 37: 40$ & 1.11 & 0.05 & 6.9 & Yes & Yes & -40 & $-35 \pm 4$ \\
\hline 3 April & $10: 47: 50$ & 1.16 & 0.11 & 6.9 & Yes & Yes & -37 & $-35 \pm 4$ \\
\hline 3 April & $10: 54: 00$ & 1.13 & 0.03 & 6.3 & Yes & No & -44 & - \\
\hline
\end{tabular}




$$
\mathrm{Z}=\sum_{\mathrm{vol}} n_{i} D_{i}^{6}
$$

where $n_{i}$ is the concentration of cloud droplets of diameter $D_{i}$. The values of $\mathrm{Z}$, determined from (2) using in situ measurements of $n_{i}$ and $D_{i}$ provided by the PMS probes aboard the aircraft, are listed in the penultimate column of Table 2 . Since the inherent errors in the derived values of $\mathrm{Z}$ are probably small compared to the other uncertainties, we have not listed them in Table 2.

In view of the previously mentioned difference in the sampling volumes of the radar and the aircraft, the general agreement between our nine derived values for $\mathrm{Z}_{e}$ and the corresponding $\mathrm{Z}$ values is unexpectedly good (Table 2).

We turn now to the sensitivity of the $35 \mathrm{GHz}$ radar in detecting cloud droplets. It can be seen from Table 2 that the clouds sampled can be divided into three categories:

1) Those not detected by the radar ( 4 cases).

2) Those detected on the A-scope but below the threshold for reflectivity measurements (12 cases).

3) Those detected and with reflectivities that were measurable ( 9 cases).

The averaged droplet spectra for these three categories of cloud are shown in Fig. 3. The first two cloud categories ("not detected" and "detected on the Ascope") are differentiated by the fact that the values of $n_{i}$ are up to a factor of 5 greater for the detected clouds than for those not detected. The third cloud category ("detected and measured") has $n_{i}$ values that reach a factor of 3 greater than for those clouds in



FIG. 3. Averaged droplet size spectra for clouds with reflectivities that were not detected by the radar (dotted line), clouds that were detected on the A-scope but were below the threshold for reflectivity measurements (dashed line), and clouds that were both detected and measured (solid line) by the $35 \mathrm{GHz}$ radar.

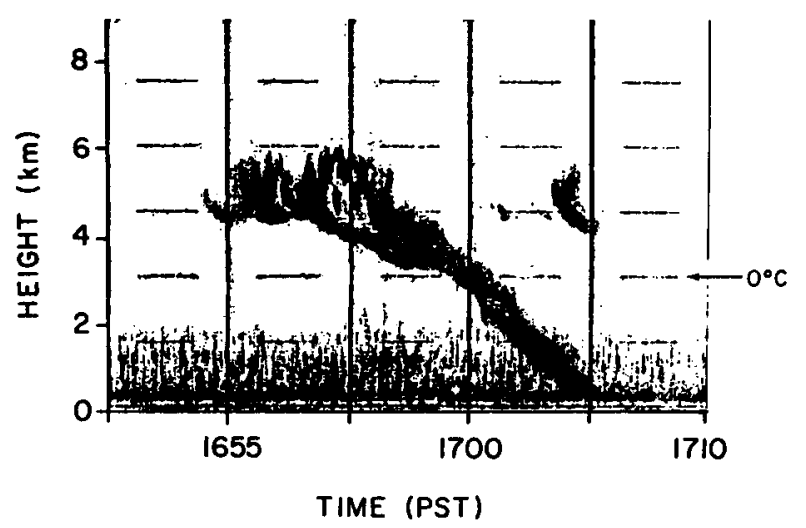

FIG. 4. Facsimile recording of an altocumulus cloud detected by the $35 \mathrm{GHz}$ radar on 11 June 1979 . The trail that descended from a height of $4 \mathrm{~km}$ to the ground was detected by the radar but was not visible to observers on the ground.

the second category, with the largest differences occurring for $D_{i}=10-20 \mu \mathrm{m}$.

Using the averaged droplet spectra for the measurable clouds, we can calculate from (2) the contribution to the value of $\mathrm{Z}$ from droplets of various sizes. Thus for droplets with diameters of $5,10,15,20$ and 25 $\mu \mathrm{m}$ the values are $-60,-47,-50,-53$ and -56 $\mathrm{dBZ}$. It can be seen from these values that the largest contribution to $\mathrm{Z}$ was derived from droplets with diameters between 10-15 $\mu \mathrm{m}$. Hence both the measurements and the theory indicate that those clouds that had sufficient reflectivity to be measurable by the $35 \mathrm{GHz}$ radar had relatively high concentrations of $10-15 \mu \mathrm{m}$ diameter droplets.

\section{b. Ice clouds}

Since $|K|^{2}$ for ice is 0.2 that of water, it follows from (1) and our previous assessment of the minimum measurable value of $\mathrm{Z}_{e}$ for a water cloud that the minimum effective radar reflectivity factor of an ice cloud that is measurable by the $35 \mathrm{GHz}$ radar at a range of $1 \mathrm{~km}$ should be $-30 \pm 4 \mathrm{dBZ}$. Hence, a cloud containing $1 \mathrm{~L}^{-1}$ of uniform-sized ice particles should be measurable by this radar at a range of 1 $\mathrm{km}$ if the ice crystals have a diameter of $\sim 100 \mu \mathrm{m}$. A cloud of such particles would have a mass content of only $10^{-3} \mathrm{~g} \mathrm{~m}^{-3}$.

The extreme sensitivity of the $35 \mathrm{GHz}$ radar to precipitation particles is illustrated in Fig. 4, which shows the echo received from an altocumulus cloud at $4 \mathrm{~km}$ altitude. While the altocumulus cloud itself was visible from the ground, the trail of ice crystals and subsequent raindrops from the cloud was invisible. The radar, on the other hand, detected the trail all the way to the ground. This sensitivity to precipitation particles may be put to good effect in cloud seeding studies (Hobbs et al., 1981). 
4. Comparisons of reflectivities measured with the $35 \mathrm{GHz}$ radar and a $5.5 \mathrm{GHz}$ radar

In this section we present the results of cloud and precipitation reflectivities measured simultaneously by the UW $35 \mathrm{GHz}$ radar and the National Center for Atmospheric Research (NCAR) $5.5 \mathrm{GHz}$ radar (the CP-4). The characteristics of the CP-4 radar are listed in Table 1 where they can be compared with the $35 \mathrm{GHz}$ radar. The measurements to be presented were obtained when both radars were pointed vertically upwards and located within $50 \mathrm{~m}$ of each other at P'oint Brown on the Pacific Coast of Washington State.

\section{a. Cloud layer with virga}

Simultaneous measurements of radar reflectivity patterns obtained with the $35 \mathrm{GHz}$ radar and the 5.5 $\mathrm{GHz}$ radar are shown in Fig. 5. These data were obtained on 8 February 1982, the target being a layer of altostratus cloud located between 1.5 and $5 \mathrm{~km}$ above the radars. The cloud layer was sufficiently thin that, on occasions, the sun's disc could just be seen through it, although thicker portions of the cloud contained virga.

Comparison of the two reflectivity patterns depicted in Fig. 5 shows that whereas the altostratus cloud layer was poorly resolved by the $5.5 \mathrm{GHz}$ radar, it

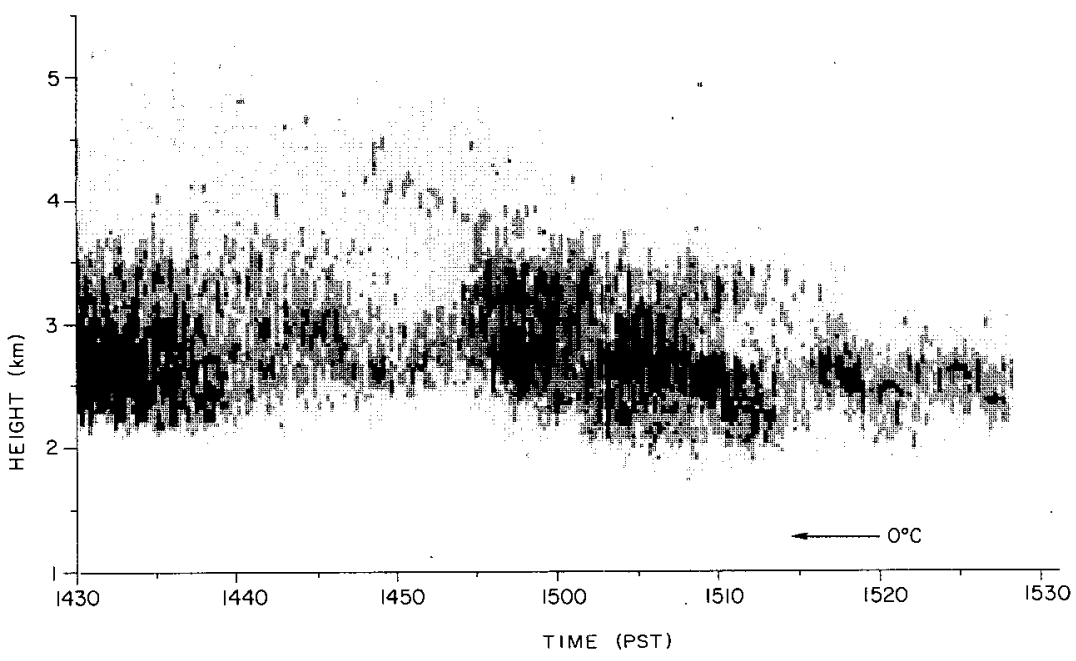

(a)

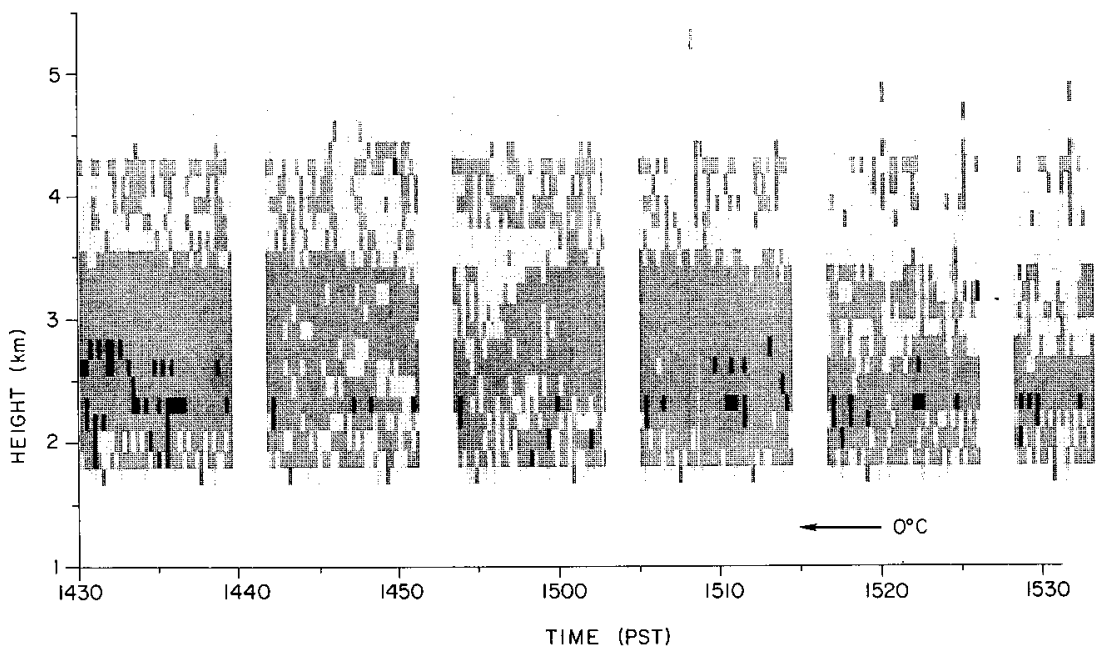

(b)

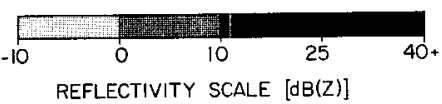

FIG. 5. Simultaneous reflectivities from a nonprecipitating altostratus cloud measured on 8 February 1982 by (a) the $35 \mathrm{GHz}$ radar and (b) the $5.5 \mathrm{GHz}$ radar. 
was readily detected, and features within it resolved, by the $35 \mathrm{GHz}$ radar. The inability of the $5.5 \mathrm{GHz}$ radar to resolve features of thin cloud such as this is due to ground clutter contamination and the relatively large beamwidth of this radar compared to the 35 $\mathrm{GHz}$ radar.

\section{b. Lightly precipitating clouds}

Simultaneous reflectivity measurements with the 35 and $5.5 \mathrm{GHz}$ radars were obtained on 12 February 1982 in light precipitation ahead of an approaching warm front. The reflectivity patterns obtained from the two radars during a $30 \mathrm{~min}$ period on this day are shown in Fig. 6. In both displays fallstreaks can be seen, which are typical of an approaching warm front (e.g. Herzegh and Hobbs, 1980). The melting layer shows up on the $35 \mathrm{GHz}$ radar data as a slight increase in reflectivity at an altitude of $\sim 0.9 \mathrm{~km}$. The melting layer is not visible in the display from the $5.5 \mathrm{GHz}$ radar because the transmit/receive switch limits the reflectivity data to $>1.5 \mathrm{~km}$ above the radar.

To facilitate quantitative comparisons, the reflectivities shown in Fig. 6 were averaged over the period 1312-1321 PST during which time the average rainfall rate at the ground was $0.02 \mathrm{~mm} \mathrm{~h}^{-1}$. A correction factor was included to account for the averaging of $\mathrm{dBZ}$ rather than $\mathrm{Z}$ values. The results are shown in Fig. 7, where it can be seen that there is reasonable agreement between the two reflectivity profiles; the greatest difference is $\sim 6 \mathrm{~dB}$, which is $2 \mathrm{~dB}$ greater than the error band on the calibration of the $35 \mathrm{GHz}$ radar reflectivity measurements. The cloud-top height determined from the two radars agreed to within 150 $\mathrm{m}$, the limit of range resolution of the $5.5 \mathrm{GHz}$ radar.

\section{c. Heavier precipitating clouds}

To compare the responses of the two radars in heavier precipitation, simultaneous data obtained on 13 February 1982, when the rainfall rates varied from $0.7-4.6 \mathrm{~mm} \mathrm{~h}^{-1}$, were analyzed. The measurements were obtained ahead of an occluded system, in which warm-sector rainbands were embedded in a stratiform cloud layer. Examples of the vertical profiles of the reflectivity measurements, averaged over two 3-min periods when the average rainfall rates were 1.5 and $4.6 \mathrm{~mm} \mathrm{~h}^{-1}$, are plotted in Fig. 8. Although the reflectivities measured by the two radars show similar variations, the reflectivities measured by the $35 \mathrm{GHz}$ radar are significantly and systematically lower than those measured by the $5.5 \mathrm{GHz}$ radar. The differences between the measurements in these heavy precipitation cases is discussed in Section 4d.

It can be seen from Fig. 8 that the top of the echoes measured by the $35 \mathrm{GHz}$ radar was as much as $2.2 \mathrm{~km}$ lower than that from the $5.5 \mathrm{GHz}$ radar.

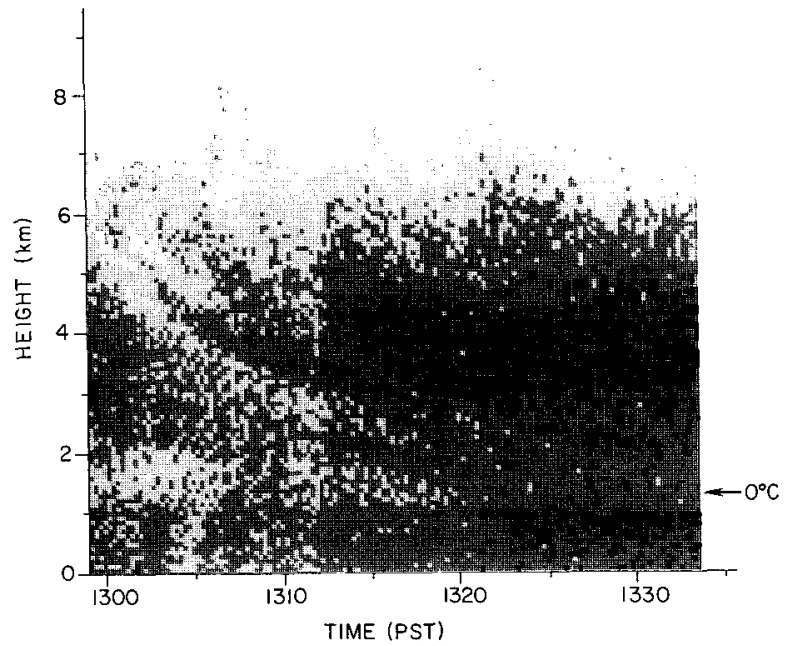

(a)



(b)



Fig. 6. Simultaneous reflectivities measured in light precipitation ahead of a warm front on 12 February 1982 by (a) the $35 \mathrm{GHz}$ and (b) the $5.5 \mathrm{GHz}$ radar.

This is partly due to the sensitivity of the $35 \mathrm{GHz}$ radar being lowered by $10 \mathrm{~dB}$ to avoid saturating the receiver and also to the higher attenuation of the 35 $\mathrm{GHz}$ radar.

\section{d. Attenuation}

Attenuation by precipitation can present a problem for radars operating at $35 \mathrm{GHz}$. This is particularly true for horizontally-scanning radars, due to the long ranges involved; vertically-pointing radars are less affected, but attenuation may still be significant.

The effects of attenuation on the $35 \mathrm{GHz}$ radar 


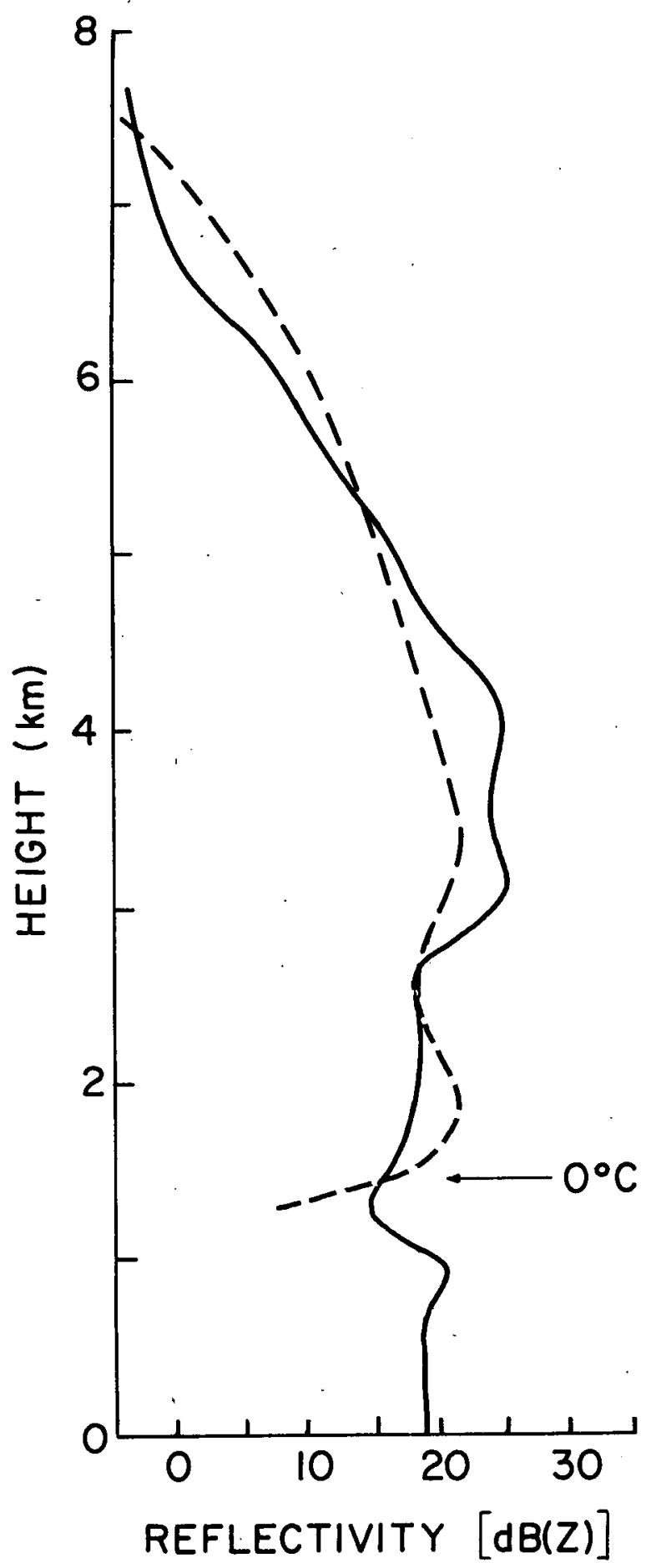

FIG. 7. Reflectivity profiles from the $35 \mathrm{GHz}$ radar (solid line) and the $5.5 \mathrm{GHz}$ radar (dashed line) averaged over the period 1312-1321 PST 12 February 1982. The average rainfall rate at the ground was $0.02 \mathrm{~mm} \mathrm{~h}^{-1}$.

can be seen in a qualitative way by comparing Figs. 7 and 8. In Fig. 7, which depicts the situation in which the average precipitation rate at the ground was only $0.02 \mathrm{~mm} \mathrm{~h}^{-1}$, the reflectivities measured by the 35 and $5.5 \mathrm{GHz}$ radars are reasonably close. However, in Fig. 8a, in which the precipitation rate was $1.5 \mathrm{~mm} \mathrm{~h}^{-1}$, the reflectivities measured by the $35 \mathrm{GHz}$ radar were lower than those measured by the $5.5 \mathrm{GHz}$ radar. This trend is seen to an even greater extent in Fig. 8b, in which the precipitation rate was $4.6 \mathrm{~mm} \mathrm{~h}^{-1}$.

Attenuation at $35 \mathrm{GHz}$ appeared to be greatest below the melting layer; above the melting layer attenuation appears less significant since the reflectivity profiles at 35 and $5.5 \mathrm{GHz}$ are more nearly parallel. This reflects the fact that attenuation through ice crystals is less than that through rain.

Measurements by Funakawa and Kato (1962) show that attenuation at $35 \mathrm{GHz}$ rarely exceeds $\sim 1 \mathrm{~dB}$ $\mathrm{km}^{-1}$ for precipitation rates typical of widespread stratiform precipitation $\left(\sim 1-5 \mathrm{~mm} \mathrm{~h}^{-1}\right)$. For a vertically-pointing radar, such as the UW $35 \mathrm{GHz}$ radar, this would cause a maximum of $6 \mathrm{~dB}$ of attenuation at a range of $3 \mathrm{~km}$. Since, as we have seen, attenuation is most prominent below the melting layer and, in typical winter storms at least, the melting layer is generally below a height of $3 \mathrm{~km}$, attenuation at 35 $\mathrm{GHz}$ should not exceed $\sim 6 \mathrm{~dB}$ in these situations.

The 12-18 dB difference in measured reflectivities between the 35 and $5.5 \mathrm{GHz}$ radars (Fig. 8) cannot be accounted for by additional attenuation in the melting layer (Joss et al., 1974), since these differences are approximately the same just above and just below the melting layer. Some of the difference in reflectivity could be due to water splashing up onto the antenna horn of the $35 \mathrm{GHz}$ radar.

\section{e. The melting layer}

The sharp increase in reflectivity measured by the $5.5 \mathrm{GHz}$ radar at an altitude of $\sim 2.5 \mathrm{~km}$ in Fig. 8 is the well-known "bright band" associated with the melting of solid precipitation. The fact that the precipitation particles were melting at this height is confirmed by the sharp increases in Doppler velocities.

A bright band also appears in the $35 \mathrm{GHz}$ measurements, but it is much less pronounced than at $5.5 \mathrm{GHz}$ and it reaches a peak value at lower altitudes (Fig. 8). A comparison of the locations of the peaks in the bright bands with the measurements of Doppler velocity shown in Fig. 8 reveals that the bright band at $5.5 \mathrm{GHz}$ is located near the top of the melting layer while the bright band at $35 \mathrm{GHz}$ is located near the base of the melting layer. Following the initial melting of the crystals near the top of the melting layer, the radar cross section of the crystals may resemble that of drops with diameters approaching the wavelength $(8.6 \mathrm{~mm})$ of the $35 \mathrm{GHz}$ radar. This would cause deviations from Rayleigh scattering and could account for the weak bright band in the 35 $\mathrm{GHz}$ radar data. 


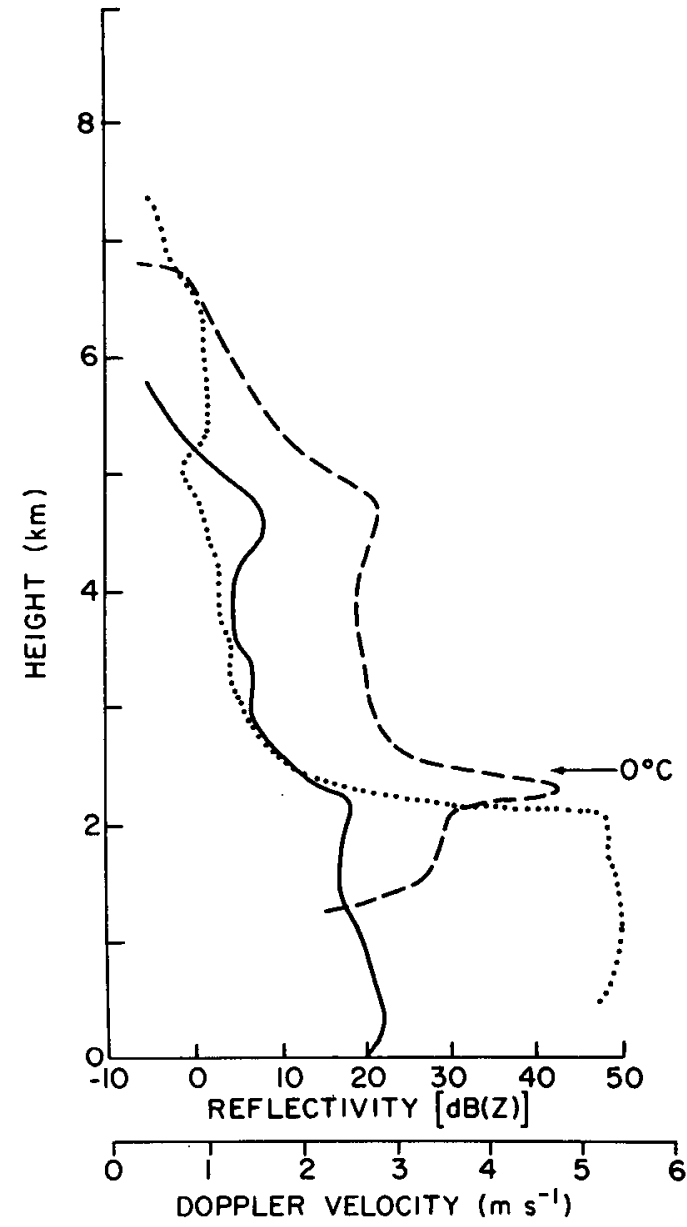

(a)

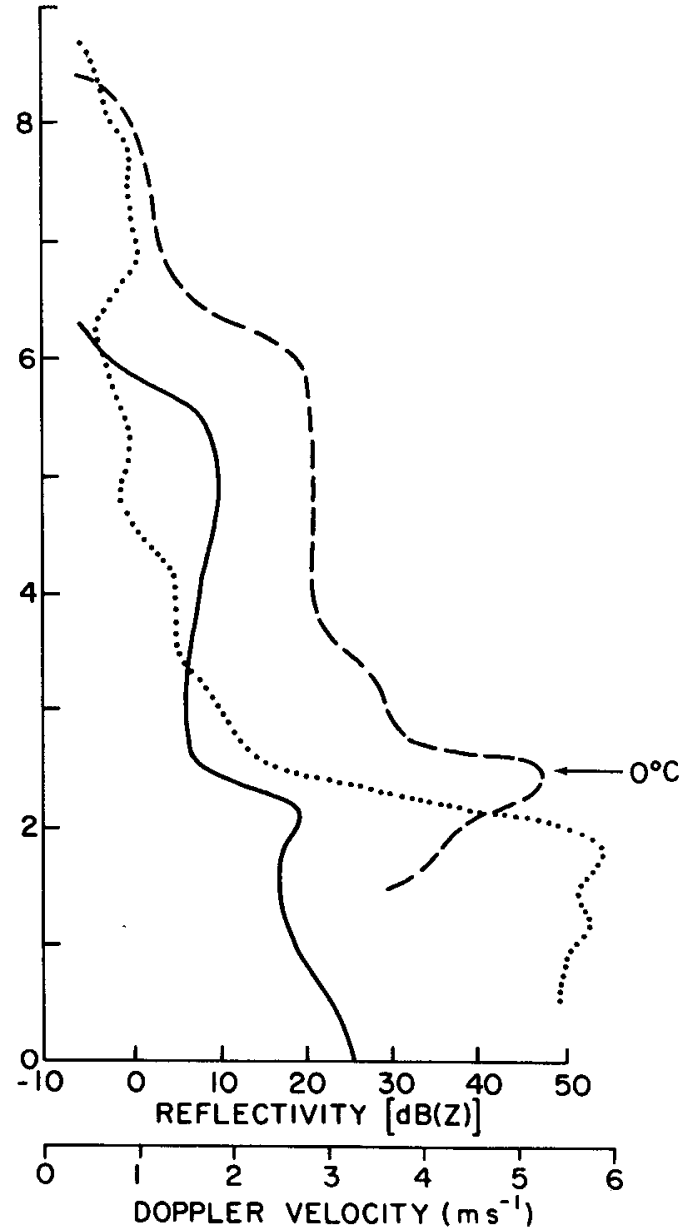

(b)

FIG. 8. Reflectivity profiles measured by the $35 \mathrm{GHz}$ radar (solid line) and the $5.5 \mathrm{GHz}$ radar (dashed line) averaged over 3-min periods from the data collected on 13 February 1982 . The rainfall rates at the ground were $1.5 \mathrm{and} 4.6 \mathrm{~mm}$ $\mathrm{h}^{-1}$ for (a) and (b), respectively. The dotted line shows the mean downward Doppler velocities of the particles as measured by the $5.5 \mathrm{GHz}$ radar.

5. Some examples of the Doppler spectra of the vertical velocity of cloud particles

\section{a. Fallspeeds of particles}

An example of the digitized radar reflectivity returns received by the $35 \mathrm{GHz}$ radar from a layer of altostratus cloud (located at $\sim 5 \mathrm{~km}$ ), a layer of altocumulus cloud (located at $\sim 3 \mathrm{~km}$ ), and a precipitation streamer is shown in Fig. 9. Some light precipitation reached the ground at the radar site (Pt. Brown on the Washington Coast) between $\sim 0615$ and 0635 PST.

Shown in Fig. 10 are the Doppler spectra measured at each of the heights indicated by the dots in the rectangles marked (a)-(e) in Fig. 9. The uppermost spectrum shown in Fig. 10a was taken above the top of the altostratus cloud layer (at $6.6 \mathrm{~km}$ ) and depicts the general level of receiver noise in the signal. The spectra at 5.4 and $4.8 \mathrm{~km}$ in Fig. 10a were taken within the altostratus cloud; they show increases in the reflectivity-weighted mean downward particle velocities, from 0.17 to $0.55 \mathrm{~m} \mathrm{~s}^{-1}$, with decreasing height in the cloud. Further increases in the mean downward velocities with decreasing height, now in the altocumulus cloud, are shown in the three uppermost spectra in Fig. 10b. The spectrum measured at the lowest height $(2.4 \mathrm{~km})$ in Fig. 10b shows a decrease in mean velocity; this was probably due to evaporation near cloud base. In Fig. 10c, which shows the spectra at $3.6 \mathrm{~km}$ between the two cloud layers, there is only receiver noise; the other two spectra, taken within the altocumulus cloud layer, show the mean particle velocities also decreasing in the downward direction with decreasing height.

The two groups of spectra shown in Fig. 10d, e follow a precipitation streamer from near the top of the altocumulus cloud layer to just above ground level. The spectra in Fig. 10d show a continuous 

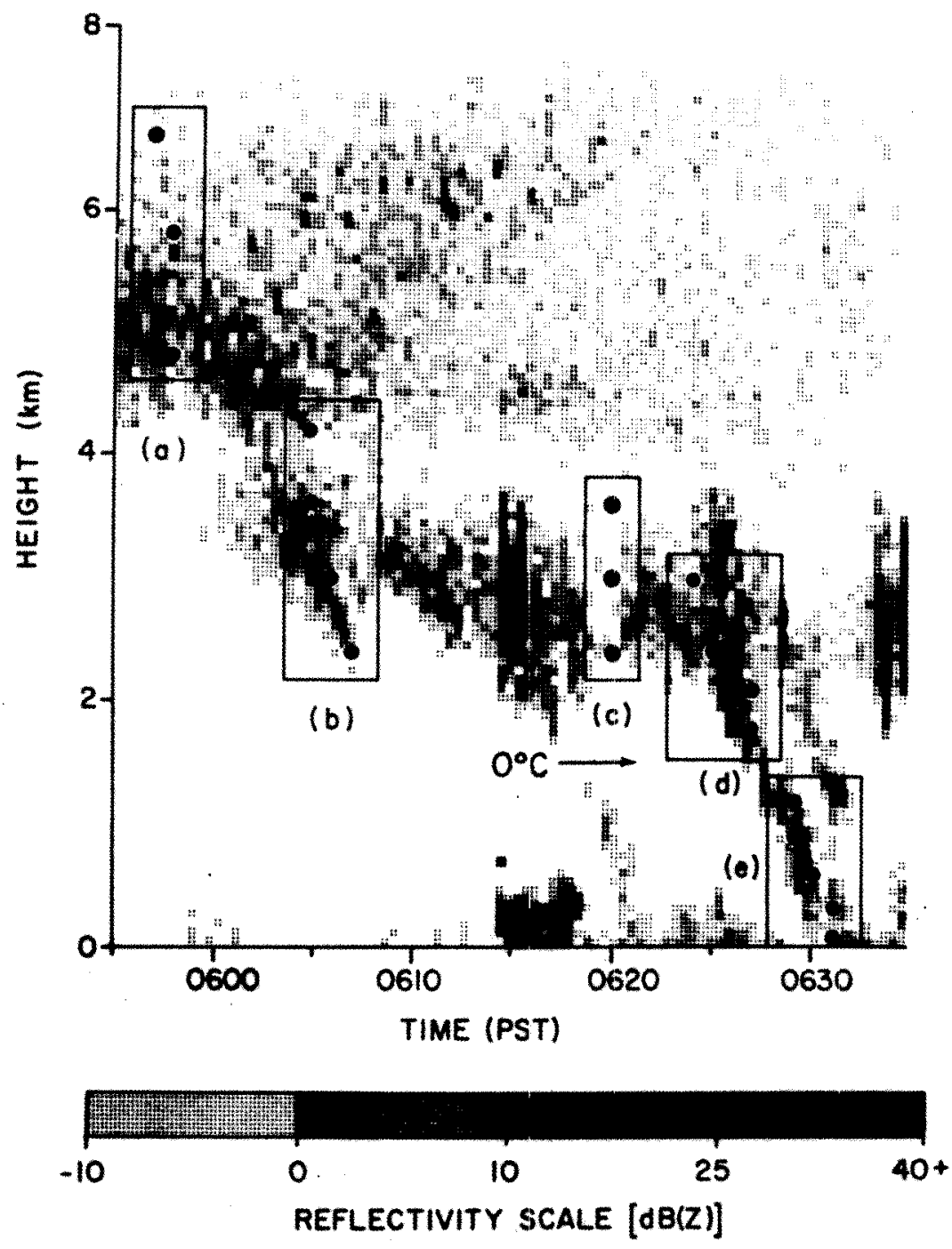

FIG. 9. Time-height cross section of the digital radar reflectivities of an altostratus cloud layer, an altocumulus cloud layer, and a precipitation streamer measured on 15 January 1982 with the $35 \mathrm{GHz}$ radar.

increase in mean downward velocity, and a slight increase in spectral width, as the height decreases from 3 to $1.8 \mathrm{~km}$. This trend continues in the top spectrum (at $1.2 \mathrm{~km}$ ) in Fig. 10e. However, between this spectrum and the next one (at $0.9 \mathrm{~km}$ ) in Fig. $10 \mathrm{e}$ there is a significant broadening and the mean downward velocity increases from 2.09 to $3.16 \mathrm{~m}$ $\mathrm{s}^{-1}$. This reflects the initial effects on the downward velocity of the melting of the ice particles as they passed from 1.2 to $0.9 \mathrm{~km}$. The mean downward velocity reaches a maximum value of $4.16 \mathrm{~m} \mathrm{~s}^{-1}$ at the next level $(0.6 \mathrm{~km})$ in Fig. 10e, where melting was probably complete. The last two spectra in Fig. 10e show decreases in the downward velocities with fall distance, probably due to evaporation of the drops.

\section{b. Upward motions of particles}

The capability of the $35 \mathrm{GHz}$ radar to resolve even finer velocity structures is illustrated in Fig. 11. Here we see both upward (positive values) and downward (negative values) moving particles within a layer of cirrus cloud.

In passing from cloud base $(\sim 5.9 \mathrm{~km})$ to $\sim 7.2$ $\mathrm{km}$, both upward and downward moving particles were detected. Thus, some of the particles were sufficiently light to be carried upwards by vertical air currents in this cirrus cloud, while other particles fell toward the ground. Above $\sim 7.2 \mathrm{~km}$, upward-moving particles dominate. Since the maximum measured upward velocity of the particles was $\sim 1 \mathrm{~m} \mathrm{~s}^{-1}$, the upward vertical air motions in this cloud must have attained at least this value. 


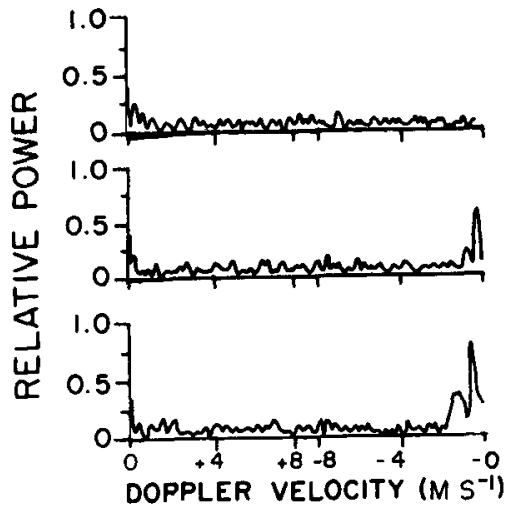

$H=6.6$

$T=0557$

$\bar{v}=0.40$

$H=5.4$

$\mathrm{T}=0558$

$\bar{v}=-0.17$

$H=4.8$

$T=0558$

$\bar{v}=-0.55$

(a)



$\mathrm{H}=4.2$

$T=0605$

$\bar{v}=-0.82$

$\mathrm{H}=3.6$

$T=0605$

$\bar{v}=-0.82$

$H=3.0$

$T=0606$

$\bar{v}=-2.01$

$$
\begin{aligned}
H & =2.4 \\
T & =0607 \\
\bar{V} & =-1.24
\end{aligned}
$$

(b)

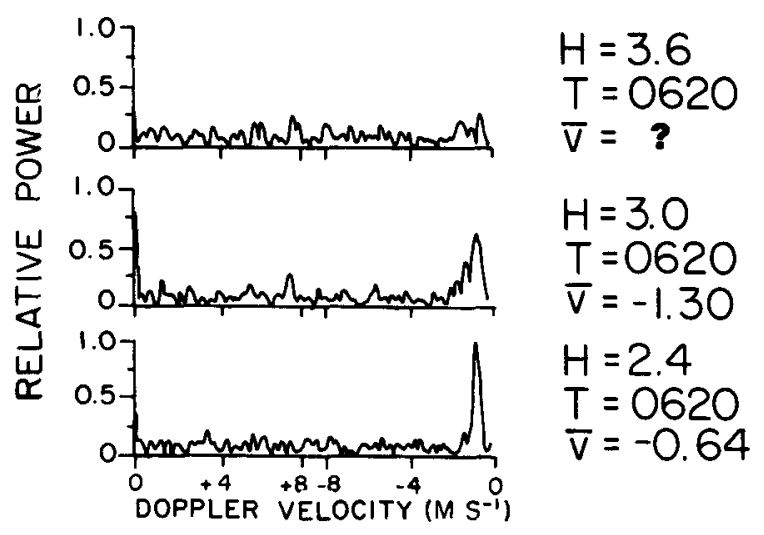

(c)



(d)

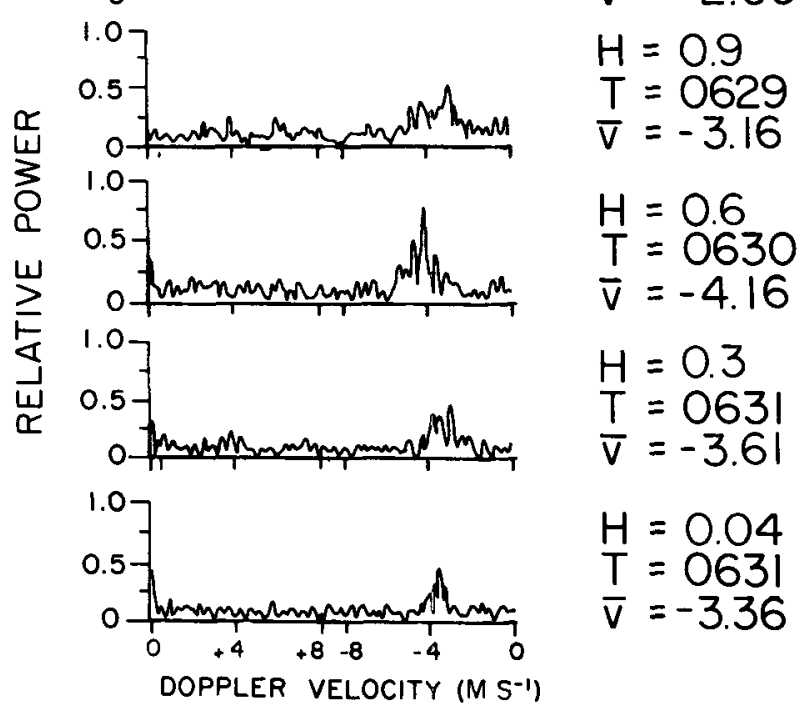

(e)

FIG. 10. Diagrams (a) through (e) show the spectra of vertical Doppler velocities measured with the $35 \mathrm{GHz}$ radar at the locations of the dots within the five rectangular areas marked (a) through (e) in Fig. 9. Positive and negative velocities indicate upward and downward motions, respectively. Height $H(\mathrm{~km})$, time $T$ (hour and min) and mean Doppler velocity $\bar{v}\left(\mathrm{~cm} \mathrm{~s}^{-1}\right)$ are shown alongside each spectrum. The prf of the radar was $4 \mathrm{kHz}$. 


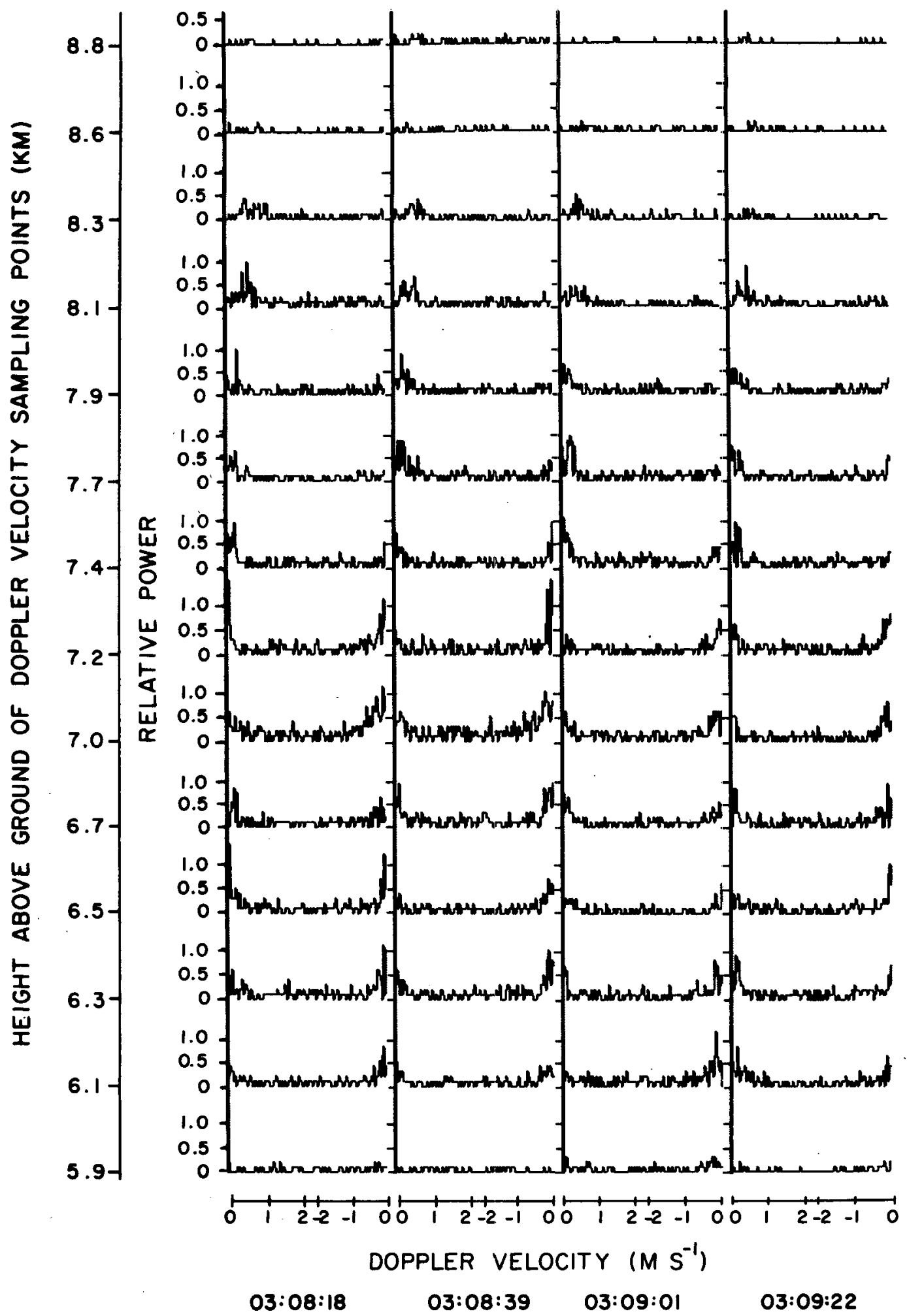

FIG. 11. Spectra of vertical Doppler velocities measured at 14 heights from 5.9 to $8.8 \mathrm{~km}$ by the $35 \mathrm{GHz}$ radar. Positive and negative velocities indicate upward and downward motions, respectively. The time (in hr:min:sec) at which the spectrum at $5.9 \mathrm{~km}$ was taken is noted at the bottom of each column of spectra. The prf of the radar was $1 \mathrm{kHz}$. 


\section{Comparisons of vertical Doppler velocities mea- sured with the $35 \mathrm{GHz}$ and a $5.5 \mathrm{GHz}$ radar}

Finally, we present the results of simultaneous measurements of vertical Doppler velocities in clouds and precipitation measured with the UW $35 \mathrm{GHz}$ radar and the NCAR CP-4 $5.5 \mathrm{GHz}$ radar. The CP4 radar utilizes a klystron amplifier, which is coupled to a pulse-pair processor to provide measurements of mean Doppler velocities (Gray et al., 1975). By contrast, the $35 \mathrm{GHz}$ radar uses the magnetron phase correlation technique. Other characteristics of the two radars are compared in Table 1.

The nonsteerable antenna on the UW radar was carefully leveled to align the axis of the radar beam as closely as possible with the vertical. The steerable antenna on the CP-4 radar was rotated around a vertical axis and the velocities averaged over each revolution. The advantage of the latter technique is that it removes any biases in the measurements of vertical velocities caused by the horizontal wind, which will be present if the radar beam is not aligned exactly in the vertical.

Simultaneous Doppler velocity measurements from the two radars were obtained on 8 February 1982. Even though reflectivities from the altostratus cloud were low (Fig. 5) good Doppler velocity measurements were obtained from both radars (Fig. 12). In Fig. 12 the Doppler measurements from the $5.5 \mathrm{GHz}$ radar are averaged over $30 \mathrm{~s}$ intervals, whereas those from the $35 \mathrm{GHz}$ radar are mean velocities computed from single Doppler spectra, which were measured every $21 \mathrm{~s}$.
It can be seen from Fig. 12 that there was generally good agreement between the fields of Doppler velocities measured by the two radars. Both radars show peak velocities at $\sim 1500$ PST at an altitude of $\sim 2.7$ $\mathrm{km}$; they also show the velocities decreasing to zero at cloud top. The $35 \mathrm{GHz}$ radar provided a more detailed view of the distribution of the particle velocities than did the $5.5 \mathrm{GHz}$ radar, and it resolved lower velocities (down to $\sim 25 \mathrm{~cm} \mathrm{~s}^{-1}$ ). Apart from the different averaging times, there are two main reasons for these differences. First, the beamwidth of the $5.5 \mathrm{GHz}$ radar is about four times greater than that of the $35 \mathrm{GHz}$ radar, and second, the pulse length of the $5.5 \mathrm{GHz}$ radar is twice that of the 35 $\mathrm{GHz}$ radar. These factors result in the $5.5 \mathrm{GHz}$ radar averaging out small-scale variations that are resolvable by the $35 \mathrm{GHz}$ radar.

\section{Summary and conclusions}

In this paper we have described the modernization of a $35 \mathrm{GHz}$ radar and have demonstrated its use in obtaining high-resolution reflectivity and Doppler velocity measurements of cloud and precipitation particles.

Calibration of the radar yielded a minimum measurable effective radar reflectivity factor of $-36 \pm 4$ $\mathrm{dBZ}$ for a water cloud at a range of $1 \mathrm{~km}$. Simultaneous in situ airborne measurements and radar measurements of water clouds yielded generally similar values for the radar reflectivity factors. They also showed that nonprecipitating clouds that were measurable with the $35 \mathrm{GHz}$ radar had higher concentra-

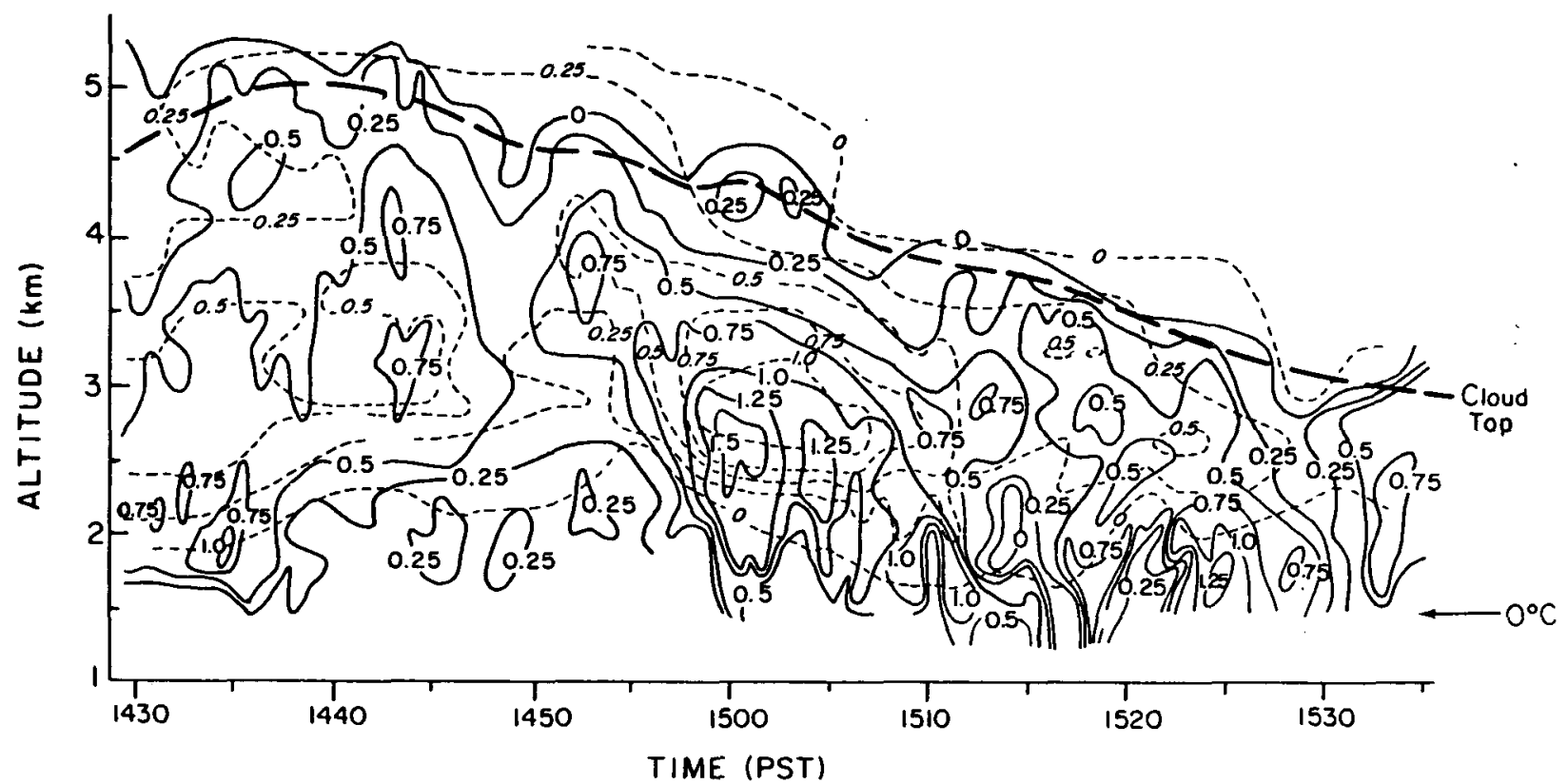

FIG. 12. Simultaneous Doppler velocities (in $\mathrm{m} \mathrm{s}^{-1}$ ) measured in an altostratus cloud layer on 8 February 1982 with the $5.5 \mathrm{GHz}$ radar (dashed lines) and the $35 \mathrm{GHz}$ radar (solid lines). All the velocities were toward the ground. 
tions of droplets than those that were not measurable, 10-15 $\mu \mathrm{m}$ diameter droplets being particularly important.

The $35 \mathrm{GHz}$ radar is also sensitive to ice crystals. Cloud containing $1 \mathrm{~L}^{-1}$ of uniformly-sized ice particles $100 \mu \mathrm{m}$ in diameter (corresponding to a mass concentration of only $10^{-3} \mathrm{~g} \mathrm{~m}^{-3}$ ) are detectable by the radar.

Simultaneous measurements of vertical profiles of reflectivity obtained with the $35 \mathrm{GHz}$ and the 5.5 $\mathrm{GHz}$ radar showed that the former can provide more detailed information on the structural features of clouds. However, attenuation at $35 \mathrm{GHz}$ can be severe $\left(\sim 0.1-1 \mathrm{~dB} \mathrm{~km}^{-1}\right.$ for precipitation rates of only $\sim 0.1-5 \mathrm{~mm} \mathrm{~h}^{-1}$ ). At $35 \mathrm{GHz}$ the radar bright band peaked at lower altitudes and closer to the height of complete melting, and it was much less pronounced than the bright band at $5.5 \mathrm{GHz}$.

The $35 \mathrm{GHz}$ radar has been Dopplerized using a new magnetron phase correlation technique. This technique was subjected to a most stringent test by using it to measure the vertical motions of particles in thin clouds with very low reflectivities. The results show that the technique can provide detailed information on the motion of particles with velocities down to $\sim 25 \mathrm{~cm} \mathrm{~s}^{-1}$.

These studies demonstrate that a $35 \mathrm{GHz}$ radar can provide valuable information on clouds and precipitation, particularly when operated in low reflectivity situations and over relatively short path lengths. Measurements of reflectivities and Doppler velocities provided by such a radar, when augmented by simultaneous airborne measurements of the structure of a cloud, can provide detailed information on particle motions and particle growth processes in clouds. Such radars are particularly valuable for studies of ice in clouds, including the effects of cloud seeding.

A.cknowledgments. We wish to thank Mr. J. Russell of our research group for the development of computer programs for displaying and processing the radar data. The measurements from the $5.5 \mathrm{GHz}$ radar were obtained by personnel from NCARs Field Observing Facility, to whom we extend our thanks; NCAR is supported by the National Science Foundation. This paper was written while one of us $(\mathrm{PVH})$ was a visiting scientist at the-Meteorological Office, Radar Research Laboratory, Royal Signals and Radar Establishment, Great Malvern, Worcester, England. This work was supported by the National Science Foundation under Grant ATM-8009203.

\section{REFERENCES}

Battan, L. I., 1973: Radar Observations of the Atmosphere, University of Chicago Press, 324 pp.

Boucher, R. J., 1959: Synoptic-physical implications of $1.25 \mathrm{~cm}$ vertical-beam radar echoes. J. Meteor., 16, 312-326.

Funakawa, K., and J. Kato, 1962: Experimental studies of propagation characters of $8.6 \mathrm{~mm}$ wave on the $24 \mathrm{~km}$ path. $J$. Radio. Res. Labs. 9, 351-367.

Gray, G. R., R. J. Serafin, D. Atlas, R. E. Rinehart and J. J. Boyasian, 1975: Real-time color doppler radar display. Bull Amer. Meteor. Soc., 56, 580-588.

Herzegh, P. H., and P. V. Hobbs, 1980: The mesoscale and microscale structure and organization of clouds and precipitation in midlatitude cyclones. Part II: Warm-frontal clouds. J. Atmos. Sci., 37, 597-611.

Hobbs, P. V., and N. T. Funk, 1984: Cloud and precipitation studies with a millimeter-wave radar: A pictorial overview. Weather, 39, 334-339.

- , J. H. Lyons, J. D. Locatelli, K. R. Biswas, L. F. Radke, R. R. Weiss Sr. and A. L. Rangno, 1981: Radar detection of cloud-seeding effects. Science, 213, 1250-1252.

Joss, J., R. Cavalli and R. K. Crane, 1974: Good agreement between theory and experiment for attenuation data. J. Rech. Atmos., 8, 299-318.

Knollenberg, R. G., 1981: Techniques for probing cloud microstructure. Clouds: Their Formation, Optical Properties and Effects, P. V. Hobbs and A. Deepak, Eds., Academic Press, 15-91.

Lhermitte, R. M., 1981: Millimeter wave doppler radar. Preprints, 20th Conf. on Radar Meteorology, Boston, Amer. Meteor. Soc., 744-748.

Nutten, B., P. Amayenc, M. Chong, D. Hauser, F. Roux and J. Testud, 1979: The Ronsard radars: A versatile C-band dual doppler facility. IEEE Trans. Geosci. Electron., 17, 281-288.

Pasqualucci, F., B. W. Bartram, R. A. Kropfli and W. R. Moninger, 1983: A millimeter wavelength dual-polarization doppler radar. J. Climate Appl. Meteor., 22, 758-765.

Paulsen, W. H., P. J. Petrocchi and G. McLean, 1970: Operational utilization of the AN/TPQ-11 cloud-detection radar. Air Force Cambridge Research Laboratories, Instrumentation Pap. No. 166, $37 \mathrm{pp}$. [Available from Air Force Geophysics Laboratory, Hanscom AFB, MA, 01731.]

Petrocchi, P. J., and W. H. Paulsen, 1966: Meteorological significance of vertical density profiles of clouds and precipitation obtained with the AN/TPQ-11 radar. Preprints, 12th Conf. on Radar Meteorology, Norman, Amer. Meteor. Soc., 467-472.

Plank, V. G., D. Atlas and W. H. Paulsen, 1955: The nature and detectability of clouds and precipitation as determined by 1.25 centimeter radar. J. Meteor., 12, 358-377.

Sauvageot, H., 1982: Small scale structure of layered clouds during PEP (1981) deduced from millimetre wave doppler radar analysis. Institut et Observatoire de Physique du Globe du Puy de Dome, Rep. No. 82-01, 14 pp.

Weiss, R. R., Sr., J. D. Locatelli and P. V. Hobbs, 1979: Simultaneous observations of cloud and precipitation particles with vertically pointing $\mathrm{X}$-band and $\mathrm{K}_{\mathrm{a}}$-band radars. IEEE Trans., GE17, 151-153.

Wexler, R., and D. Atlas, 1959: Precipitation generating cells. $J$. Meteor., 16, 327-332. 